\section{Phosphatase, Saure}

S. Holdenrieder ${ }^{1}$ und P. Stieber ${ }^{2}$

${ }^{1}$ Institut für Laboratoriumsmedizin, Deutsches Herzzentrum München, Klinik an der Technischen Universität München, München, Deutschland

${ }^{2}$ Institut für Laboratoriumsmedizin, Klinikum der Universität München (LMU), München, Deutschland

\section{$\operatorname{Synonym}(e)$ SP}

Englischer Begriff acid phosphatase

Definition Die saure Phosphatase des Serums stellt eine Gemisch aus 5 Isoenzymen dar, mit einer maximalen enzymatischen Aktivität bei einem $\mathrm{pH}<7,0$.

Struktur Die saure Phosphatase lässt sich unterteilen in eine Gruppe Tartrat-resistenter (aus Osteoklasten) und Tartrathemmbarer Phosphatasen (aus Thrombozyten und Prostata).

Synthese - Verteilung - Abbau - Elimination Die Isoformen der sauren Phosphatase stammen aus Thrombozyten, Erythrozyten, Zellen des retikuloendothelialen Systems, Knochen und Prostata. Sie sind v. a. in den Lysosomen lokalisiert und spalten Phosphatester bei einem $\mathrm{pH}<7,0$.

Funktion - Pathophysiologie Die Tartrat-resistente saure Phosphatase im Serum ist physiologisch bei Heranwachsenden und pathologisch bei Erwachsenen mit Knochenabbau und -umbau, z. B. bei Frauen mit metastasierenden Karzinomen erhöht. Die Tartrat-hemmbare saure Phosphatase wird vermehrt bei Prostatahyperplasie, Prostatitis und beim Prostatakarzinom ins Serum freigesetzt.
Untersuchungsmaterial - Entnahmebedingungen Serum, Plasma (kein Heparin und Oxalat).

Referenzbereich - Erwachsene 4,8-13,5 U/L (methodenabhängig).

\section{Indikation}

- Verdacht auf Karzinome und Metastasen des Knochens

- Morbus Gaucher

Interpretation Erhöhte Werte der sauren Phosphatase können Indikatoren von Erkrankungen des Skelettsystems, des retikulo-endothelialen Systems sowie des Prostatakarzinoms sein. Allerdings ist zu berücksichtigen, dass jede Manipulation der Prostata (rektale Untersuchung, Blasenkatheterisierung, Fahrrad fahren etc.) sowie eine Hyperplasie oder Entzündung der Prostata eine vermehrte Freisetzung der sauren Phosphatase bedingen können. Aufgrund des besseren Sensitivitäts-Spezifitäts-Profils wird heutzutage bei Verdacht auf ein Prostatakarzinom anstelle der Gesamt-SP oder der Tartrat-hemmbaren SP die Bestimmung des PSA ( $\triangleright$ Prostataspezifisches Antigen) bevorzugt.

\section{Diagnostische Wertigkeit}

- Verdacht auf Karzinome und Metastasen des Knochens

- Morbus Gaucher (Sphingolipidose)

\section{Literatur}

Thomas L (2005) Saure Phosphatase. In: Thomas L (Hrsg) Labor und Diagnose, 6. Aufl. TH-Books, Frankfurt am Main, S 118-120 